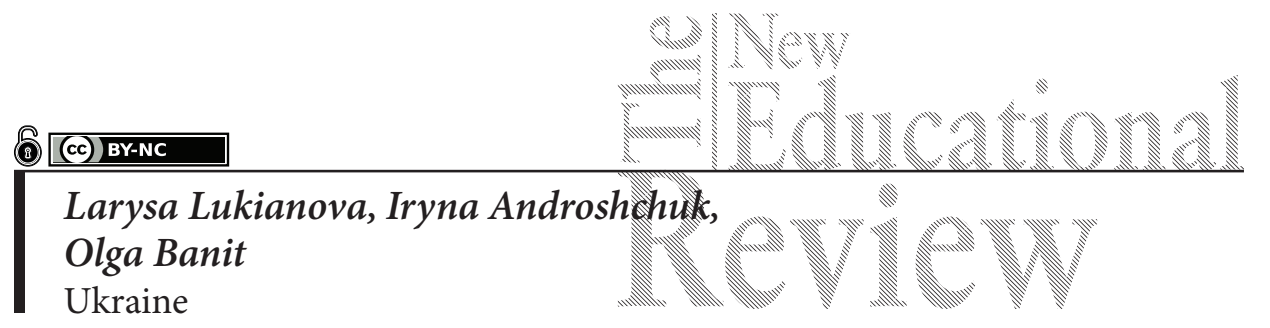

\title{
Time Management as a Pedagogical Technology of PhD Students' Effective Self-Management
}

DOI: 10.15804/tner.2019.56.2.04

\begin{abstract}
The article reveals the importance of the time management problem and substantiates the expediency of its research. It describes peculiarities of time management as a pedagogical technology concentrating on its principles; analysis of technology genesis was carried out in the works by foreign and domestic scientists from different fields of science. Five groups of problems solved with the help of this technology were identified. It was found out that time management within our research meets the requirements of a pedagogical technology effectively facilitating $\mathrm{PhD}$ students' self-management. It was proved that it combines features of professional management technology as well as effective self-management.

The research analyzed the influence of training sessions ( 36 hours) devoted to the development of time management skills (professional and personal) at the level of postgraduate students' time management competence formation. There was ground to conclude that the conducted training sessions had a positive effect on the increase in all the indicators peculiar to the mentioned competence confirming the efficiency of time management technology in the process of $\mathrm{PhD}$ students' self-management.
\end{abstract}

Keywords: PhD student, pedagogical technology, effective self-management, time management 


\section{Introduction}

The modern world is characterized by dynamism, rapid development of innovative technologies, and continuous socio-economic changes. The increased pace of these changes requires greater assignment scopes, adoption of independent decisions, and therefore, modern specialists' ability to organize and plan their activities, to find time reserves for the realization of not only professional but also personal goals. Thus, the living environment of today is about strengthening the requirements for rational time organization.

It should be noted that the category of time in general has been a primary concern in philosophical, sociological, and psychological studies.

Time is of great value today. Therefore, looking for its definition, the ability of its rational allocation, it is worth taking into account the complexity and multiplicity of human experience contributing to this concept development as well as field-specific distinctions in its interpretation.

Society globalization and the rapid pace of life create psychological tension conflicting with emotional experiences, which often results in a disorganized working process negatively affecting degree-seeking students' education. The limited scope of the article does not allow for considering the problem under examination for all degree-seekers. Thus, our research is going to be focused on one group only - PhD students. We consider this category of applicants as one deserving special attention.

One of the most important skills that have to be acquired by $\mathrm{PhD}$ students over the course of their studies is the capacity for continuing education. To achieve the goal it is necessary to learn rationally, to perform any mental activity within the shortest time possible, and effectively plan time for its implementation. All the above-listed points are important since it is rationally organized work that directly affects the success of the post-graduate student's further personal and professional growth. Under pressure of time, such students have to seek, analyze, synthesize, process and transfer large amounts of information, participate in experimental activities.

Modern demanding requirements imposed on $\mathrm{PhD}$ students make them learn to be able to prioritize independently (without consulting a scientific supervisor), to find a balance between private (family) life, workload and research making time for work, study, hobbies and leisure. Thus, one of post-graduate students' priority tasks is effective time planning at any level-personal, team, corporate, as well as the ability to coordinate their actions with the actions of others in order to perform set challenges. 
Therefore, in PhD students' professional activity connected with intense mental processes, the question of effective self-management is actualized.

Self-management, as noted by K. Bischof and A. Bischof, is not only the ability to properly plan their activities and rationally use working time and resources, but also conscious acceptance of responsibility for one's destiny, career, and success (Bischoff, 2006, p. 8). Continuous improvement of the planning process of one's own activities, rationalization of actions, the ability to work with information in a timely manner, present research results, communicate and establish connections - all these factors ensure the most efficient activity of the post-graduate student.

In our opinion, the technology of "time management" should hold a specific place in this process because it has a huge educational and managerial potential largely contributing to the outlined problem solution.

Time management technology meets the basic methodological requirements conceptuality, systemic character, efficiency and reproducibility. Consequently, internalization of this technology opens up great opportunities for using rational techniques of acquiring and processing new information, which enables postgraduate students to pursue any intellectual activity within the shortest possible time and without putting in great effort. Time management involves conscious control over time, the use of various methods, tools for fulfilling specific tasks, projects, and goals. The time-management system covers a number of successive processes, namely: planning, information distribution, determination of goals and objectives, delegation, analysis, monitoring, listing, prioritizing in order to maximize results in professional and personal growth.

In time management, not only the formation of necessary skills is important but also the use of methods, adequate goal setting, pre-planning, and rationally organized work.

It is worth noting that the technological approach to time management is in the scope of researchers' scientific interests from different fields of science and practice.

\section{Research Problem}

In the middle of the last century, the problem of personal time management became an independent branch of knowledge of general management. A significant contribution to the study of this problem was made by P. Drucker, an American scientist (the 60s of the twentieth century). In the works devoted mainly 
to the activities of managers, the scientist emphasized the fact that for scientists and researchers engaged in mental work the main means of improving efficiency is time management: “...The knowledge worker must be focused on the results and performance goals of the entire organization to have any results and performance at all. This means that he has to set aside time to direct his vision from his work to results, and from his specialty to the outside in which alone performance lies..." (Drucker, 2006, p. 30).

In the late $20^{\text {th }}$ - early $21^{\text {st }}$ century, the studies by D. Allen, B. Tracy, J. Yager, F. Kay and others became essential in the development of time management. In particular, the American personal productivity consultant, author of one of the effective time management methods, D. Allen, claims that "It's possible for a person to have an overwhelming number of things to do and still function productively with a clear head and a positive sense of relaxed control. That's a great way to live and work, at elevated levels of effectiveness and efficiency. It's also becoming a critical operational style required of successful and high-performing professionals" (Allen, 2001, p. 3). Similar ideas can be found in the works by J. Yager (Yager, 1999), F. Kay (Kay, 2003), D. S. Kennedy (Kennedy, 2013), emphasizing the idea that to effectively allocate time means to organize one's life in a proper way. People who manage time not only successfully build global plans, but also quickly implement them.

A famous Canadian psychologist, writer and entrepreneur, B. Tracy, treats time as the most valuable asset, an indispensable and non-renewable resource. He claims that a person's future is determined by the ability to manage their time: "Your ability to manage your time, as much as any other practice in your career as an executive, will determine your success or failure. Time is the one indispensable and irreplaceable resource of accomplishment. It is your most precious asset. It cannot be saved, nor can it be recovered once lost. Everything you have to do requires time, and the better you use your time, the more you will accomplish, and the greater will be your rewards. Time management is essential for maximum health and personal effectiveness. The degree to which you feel in control of your time and your life is a major determinant of your level of inner peace, harmony, and mental well-being" (Tracy, 2016, p. 2).

Given that the postgraduate student's long-term activity using digital training tools causes a significant reduction in motor activity, psyche inhibition, performance blockage, deterioration of attention, and memory that accelerates fatigue, causes apathy and, ultimately, the chronic fatigue syndrome, there is a need for effective time allocation not only to improve work efficiency and effectiveness but also to maintain mental and physical health. 


\section{Theoretical Background}

Time management as a pedagogical technology is now treated by scientists from different points of view.

We are going to consider some of them in more detail.

1. In the traditional sense, a pedagogical technology is an organizational and methodological framework for the pedagogical process comprising a complex of psychological and pedagogical patterns that determine a special set and combination of forms, methods, media, techniques of teaching, educational means, etc. According to this point of view, the technology of "time management" in its essence is of pedagogical nature as it covers all the components of the pedagogical process: purpose, task, contents, principles, methods, forms, tools, results and their evaluation.

All these components are determined on the basis of stating the purpose (goal) and the correlated result. In our study, the goal of time management as a pedagogical technology is to develop in $\mathrm{PhD}$ students the competences associated with high-level self-management, including self-organization of activities, which results in raising their professional activity efficiency and optimizing their work capacity.

To use the outlined technology, it is equally important to properly determine the tasks. Based on the analysis of the time management of tasks identified by the modern researchers, we can combine them into several groups. The first group of tasks is connected with the development of the capacity for rational time allocation as a gradual planning component. The second group covers the effective component of the time management structure involving decision-making based on the definition of effective and productive activities. The third group is a practical component of time management aimed at organizing and implementing the tasks, performing them at specified intervals. The fourth group as a monitoring component makes it possible to trace the effectiveness of the sequence of actions involving control that can be carried out through the analysis of how the planned activity is fulfilled on a daily basis and its optimization. A separate group of tasks is rational time management of professional, educational activities, hobbies and leisure.

First of all, the pedagogical "time management" technology complies with the following main methodological principles - conceptuality, consistency, and reproducibility. The conceptual nature of this technology is connected with the fact that it relies on the scientific concept of self-organization involving the philosophical, psychological, didactic and socio-pedagogical determination of the goal definition and its fulfillment. Consistency ensures purposefulness, predictability 
and logic behind all processes, the interconnection of all components, and the integrated approach to combining theoretical and practical activities. Based on the above-mentioned, we can conclude that time management like any other pedagogical technology involves the construction of a certain process algorithm, the definition of a set of goals together with the contents of the PhD student's individual activity organization in accordance with the requirements of professional competence ensuring the expected outcomes realization. Reproducibility should be understood as the possibility of applying time management as a pedagogical technology (or its repetition, reproduction) by various subjects under changed conditions.

2. In another context, "time management" can be considered as a sequence of targeted actions based on the use of educational techniques aimed at ensuring effective time use. Therefore, for postgraduate students, such a technology is the organizational and technical component of both the educational process and free time organization characterized by the following main features: algorithmic nature of professional activity self-organization; uniqueness of personal style peculiar to each $\mathrm{PhD}$ student; projection of the result implying post-graduate students' constant readiness to make optimum use of time in the future professional and personal life.

This approach is based on the definition of the concept "pedagogical technology" presented in the UNESCO glossary of terms (Glossary, 1986, p. 43).

3. Analysis of the source based on the problem under examination gives ground to conclude that "time management" also belongs to the technologies of professional development. The $\mathrm{PhD}$ student is assigned the role of an independent subject interacting with the environment. This interaction includes all stages of activity, each of which affects the formation and development of $\mathrm{PhD}$ students' professional competence. In this respect, motivation is important as well as cognitive interest, individual experience, creative needs, the need for self-improvement and axiological potential.

Effective use of time management as an effective self-management technology involves taking into account $\mathrm{PhD}$ students' personal qualities such as their biological clock, the way of thinking, temperament, etc. Using such an approach in organizing and planning one's own time will help maximize productivity. In addition, it is necessary to take into account postgraduate students' individual characteristics which depend on external factors and may be distracting while performing mental activity and significantly reduce its productivity, in particular: attitude to noise, ability to perform monotonous work, ability to switch from one type of activity to another, etc. 


\section{Research Methodology}

Our research was conducted over the period 2017-2019, using questionnaires, conversations and interviews. PhD students studying at scientific institutions of the National Academy of Pedagogical Sciences of Ukraine participated in the survey on a voluntary basis. The sample of respondents comprised 156 people. The collected data was anonymous, used only for the research purposes and were not connected with the results of postgraduate training.

The selected research tool was a questionnaire consisting of 15 questions. The main focus was on the study of the level of the need for the time management competence formation in postgraduate students. The questions and statements were formulated accordingly: "Do you want to learn as much as possible about different approaches to using time management technology?", "Do you want to work out your own planning system that will allow you to easily adapt to external changes?", etc.

In addition to these questions, it was planned to investigate the postgraduate students' attitude toward time management technology, using the following statements:

- I think that every student should be engaged in self-development on a regular basis, investing time in corresponding activities.

- I consider it necessary to acquire the competence of evaluation of expected research activity results and the time spent implementing them, etc.

The postgraduate students responded to each question and statement in the questionnaire based on the overall psychometric assessment according to the Likert scale. In accordance with this scale, each student was asked to evaluate their attitude to the subject under examination based on simple, consistent judgments within the following framework: from one critical point "yes" through a neutral one to the opposite critical point - "no". The sum of evaluations of each individual statement allowed for determining the formation level of the need for time management in the PhD students. The questionnaire was followed by individual interviews with 12 randomly selected $\mathrm{PhD}$ students -6 from each scientific institution. As a result of the research, we collected considerable empirical material characterizing the studied variables.

\section{Research Results}

According to the results of the survey, at the beginning of postgraduate studies (2017), the formation level of the need for the time management competence was quite high. The largest number of the respondents $(82.1 \%)$ mentioned the need 
for the ability to combine work, study and leisure. The smallest number of $\mathrm{PhD}$ students $(41.2 \%)$ noted that they were working on a systematic approach to the management of professional and personal time. The latter set the task to create a system of training sessions which would contribute to the formation of the time management competence.

During 2018, a series of training sessions (36 hours in total) was conducted, aimed at motivating the $\mathrm{PhD}$ students to master and use time management technology in their personal lives and professional activities. Having given such training, in 2019 the second questionnaire was administered, the results of which significantly differed from the original ones.

The results of the responses to some items of the questionnaire are shown in the graphs below.

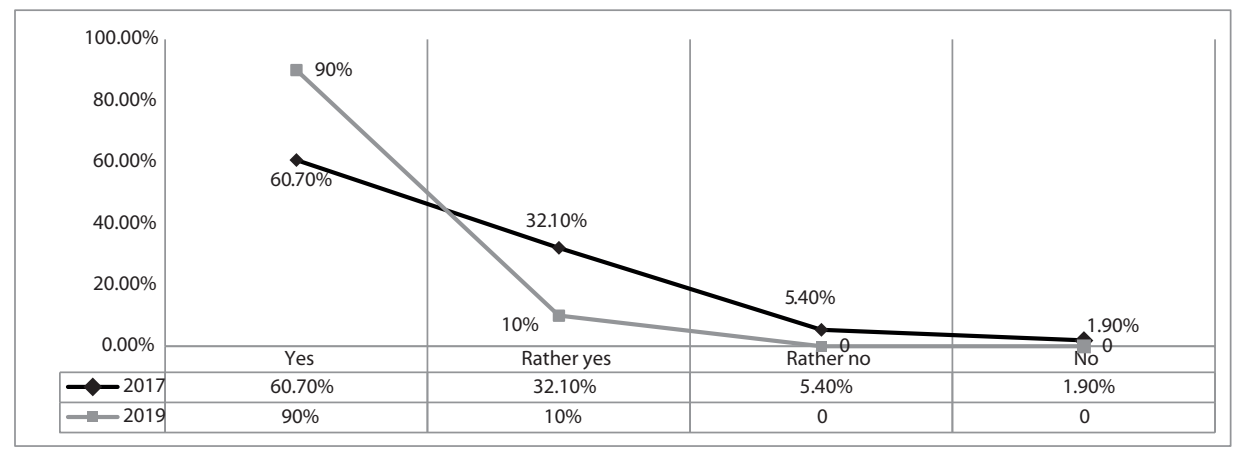

Figure 1. The results of the comparative analysis of the answers to the statement "I want to acquire systemic knowledge on the use of time management technology" (2017 and 2019)

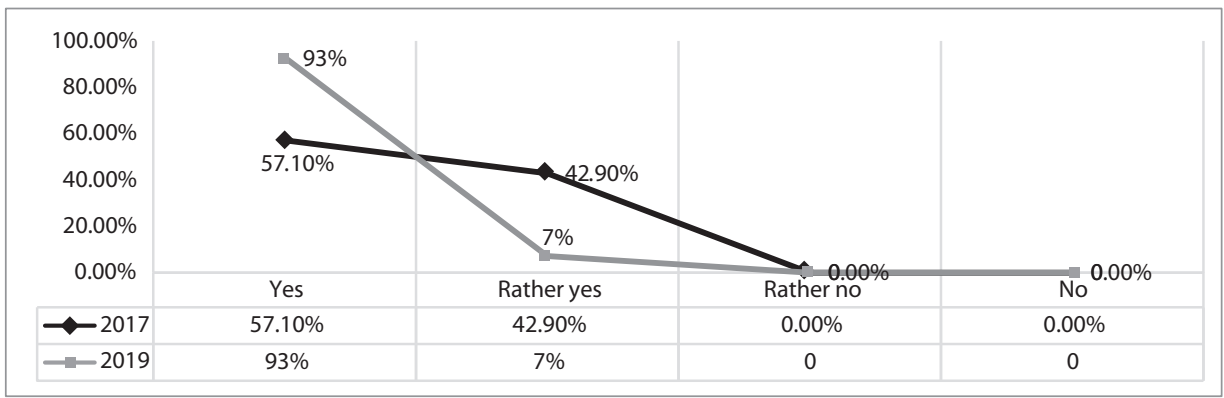

Figure 2. The results of the comparative analysis of the answers to the statement "I want to work out my own planning system, which will allow me to adapt easily to external changes" (2017 and 2019) 
As seen in Figure 1, in 2019 the number of PhD students who had the desire to acquire systemic knowledge on the use of time management technology tripled.

Figure 2 shows that in 2017 the $\mathrm{PhD}$ students expected to create their own planning system that would help them to adapt to external changes, but in 2019 their number almost doubled.

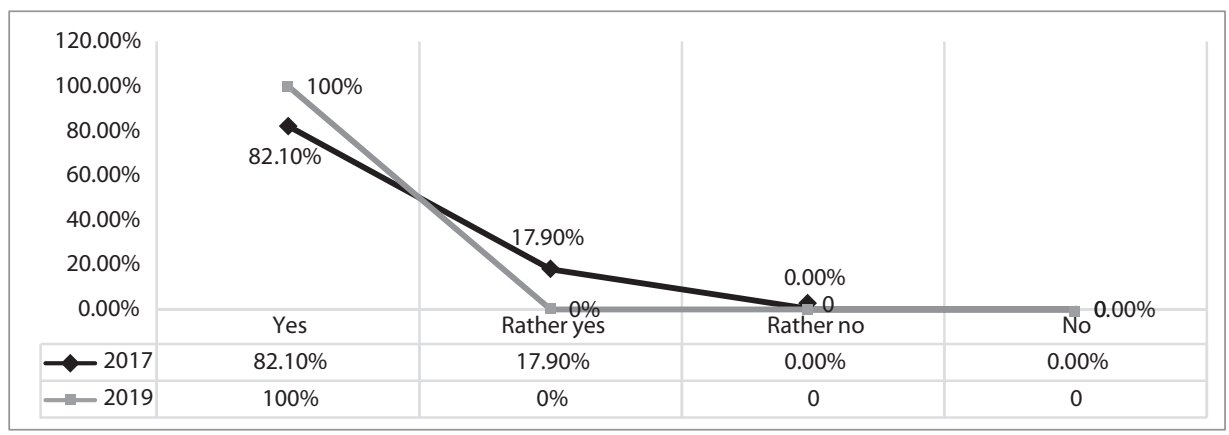

Figure 3. The results of the comparative analysis of the answers to the statement "I want to learn how to best combine work, study and leisure" 2017 and 2019

The importance of time management technology as a health-saving one is presented in Figure 3. From Figure 3 it is evident that in $2019100 \%$ of the $\mathrm{PhD}$ students expressed a desire to learn how to best combine work, study and leisure.

The results shown in the following two figures (Figure 4 and Figure 5) are also illustrative. $93 \%$ of the $\mathrm{PhD}$ students believe that by the time of graduation, it is necessary to master time management technology. $100 \%$ of the respondents

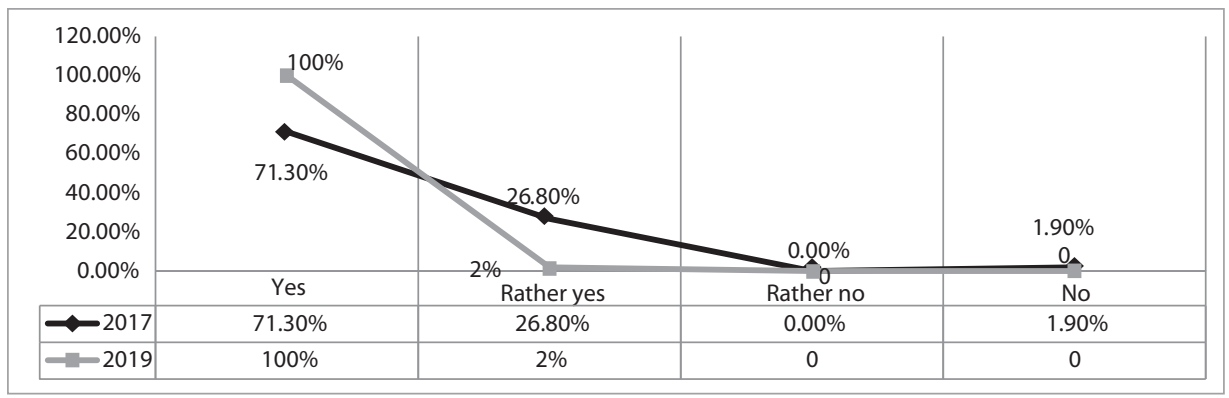

Figure 4. The results of the comparative analysis of the answers to the statement "I believe that by the time of graduation it is necessary to master time management technology (2017 and 2019) 


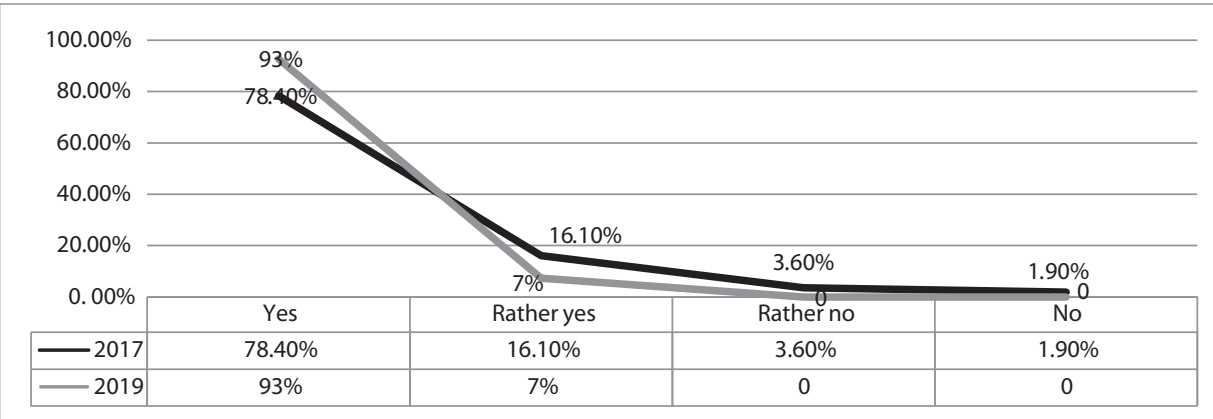

Figure 5. The results of the comparative analysis of responses to the statement "I believe that every post-graduate student should be engaged in self-development on a regular basis, using time management technology (2017 and 2019)

I consider it necessary to acquire the competence of evaluation of expected research activity results and the time spent on their implementation

I want to develop the ability to set goals in educational, cognitive and professional activity and...

I want to work out my own planning system that will allow me to easily adapt to external changes

I think every student should be engaged in selfdevelopment on a regular basis, investing time in corresponding activities

I want to timely perform planned and unplanned tasks

I believe that by the time of graduation it is necessary to master time management technology

I want to learn how to combine work, study and leisure

I want to get systematic knowledge on the use of time management technology

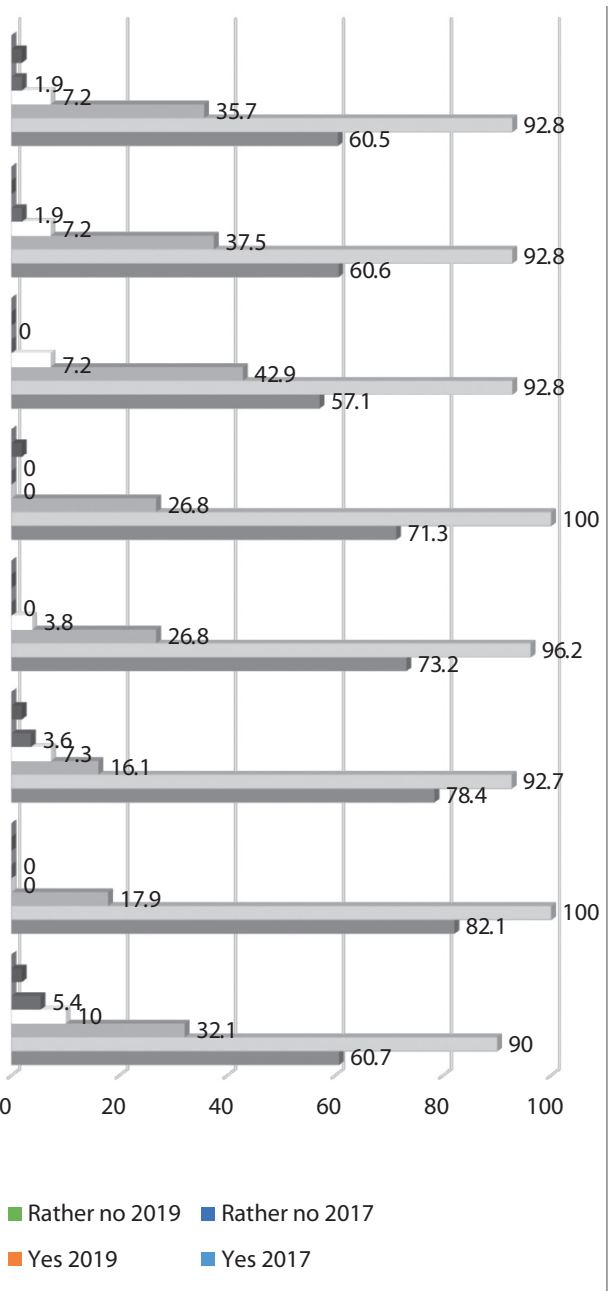

Figure 6 . The generalized results of the survey 
consider it essential to be systematically engaged in self-development using the above-mentioned technology.

The bar chart (Figure 6) presents the generalized results of the survey.

Based on Figure 6, it is clear that the positive dynamics of changes in the $\mathrm{PhD}$ students' formation level of the need for the time management competence was made possible as a result of their active participation in the training sessions.

In general, the data obtained from the repeated diagnostics results show that the average number of the respondents who gave the "yes" answer increased by $28 \%$, "rather yes" answer decreased by $23 \%$. In the final data, there was no "rather no" or "no" answer, which of course confirms the effectiveness of time management as pedagogical technology.

While processing the results of the $\mathrm{PhD}$ students' questionnaire, as well as conversations and interviews prior to the time management training and after it, we identified three levels of the time management competence development: high, average and low.

The high level of this competence formation is characterized by clearly expressed motivation to systematically master time management technology; the interest in education throughout life, the desire to analyze, systematize, compare, and improve.

The average level of skills in time management is characterized by the interest in obtaining new knowledge, but mastering the technology lacks a systemic character resulting in reduced effectiveness of optimal time use.

The low level of the competence development is characterized by weak motivation, lack of a positive and active attitude to the time management problem, and lack of desire to improve its existing level.

Evaluation of the results

Processing of the results:

(for each answer):

"Yes" - 3 points;

30-45 points - high level;

"Rather yes" - 2 points;

17-29 points - average level;

"Rather no" - 1 point;

$0-16$ points - low level

"No" - 0 points.

The generalized results are presented in Table 1. 
Table 1. Development levels of the time management competence in the $\mathrm{PhD}$ students

\begin{tabular}{lcccc}
\hline \multirow{2}{*}{$\begin{array}{c}\text { Development } \\
\text { levels }\end{array}$} & \multicolumn{2}{c}{2017} & \multicolumn{2}{c}{2019} \\
\cline { 2 - 5 } & $\begin{array}{c}\text { Number of } \\
\text { students }\end{array}$ & $\%$ & $\begin{array}{c}\text { Number of } \\
\text { students }\end{array}$ & $\%$ \\
\hline High & 105 & $67 \%$ & 145 & $93 \%$ \\
\hline Average & 36 & $23 \%$ & 11 & $7 \%$ \\
\hline Low & 15 & $10 \%$ & - & - \\
\hline
\end{tabular}

Thus, as evidenced by the analysis results, following the application of time management pedagogical technology the high formation level of the time management competence increased in $40 \mathrm{PhD}$ students, the average level decreased in $25 \mathrm{PhD}$ students and the low level was not observed at all confirming the effectiveness of the chosen technology

\section{Conclusion}

The analysis of the works of domestic and foreign scholars gave ground for the conclusion that the time management technology is considered from the standpoint of philosophy, psychology, pedagogy and management. It has been found out that the time management technology is effective in the process of managing free time by $\mathrm{PhD}$ students, who need effective self-organization, rational use of time in order to combine studying with scientific activity and hobbies. The analysis and processing of the research results proved that as a result of conducting the training aimed at fostering the level of the corresponding competence development, its high level has increased resulting in a decrease in the average level and its low level was not revealed at all.

The study does not exhaust all aspects of the identified problem. The prospect of further research is seen in the systemic approach to the study of the importance of the time management technology in the scientific and personal growth of future scientists.

\section{References}

Allen, D. (2001). Getting Things Done. The Art of Stress-Free Productivity. New York: Published by the Penguin Group.

Drucker, P. (2006). Effective Executive. New York: An Imprint of Harper Collins Publishers. 
Glossary of education technology terms. (1986). Paris: United Nations Educational, Scientific and Cultural Organization.

Kay, F. (2003). Kickstart Your Time Management: The Complete Guide to Great Work Habits. Oxford: John Wiley and Sons Ltd

Kennedy, D.S. (2004). Time Management for Entrepreneurs: The Ultimate No Holds Barred Kick Butt Take No Prisoners Guide to Time Productivity and Sanity Paperback. Printed in Canada: Entrepreneur Press.

Tracy, B. (2016). Time management. Moscow: Mann, Ivanov and Faber.

Yager, J. (1999). Creative Time Management for the New Millennium. Stamford: Hannacroix Creek Books. 